\title{
University students' perceptions of multilingual education: A case study of the North-West University Mafikeng campus
}

\author{
Abigail Hlatshwayo and Liqhwa P. Siziba \\ Department of English, North-West University, Mafikeng Campus, South Africa \\ E-mail: abigail.hlatshwayo@nwu.ac.za; liqhwa.siziba@nwu.ac.za
}

\begin{abstract}
The dominant position of neo-liberal monolingual medium-of-instruction practices has created myths and fallacies about the utility of English as the sole language of skills development and training in South Africa (Ndhlovu 2013:33). As a result, most tertiary institutions are reluctant to implement multilingual education for purposes of teaching and learning because they want to create "globally relevant" students. This argument is based on myths and has been proven by many scholars to be delusive. Current research has proven that the use of multilingualism in higher learning contributes to the learner's conceptual and pedagogical development as well as his/her communicative competence. However, despite this evidence, the North-West University's (NWU) Mafikeng campus is failing to implement a language policy that promotes multilingualism. A commonly-heard argument is that the students at NWU have a negative attitude towards the use of their indigenous languages for teaching and learning purposes. It is in light of this that the researchers set out not only to interrogate the NWU language policy, but also to go a step further and investigate the students' perceptions of multilingual education as a factor contributing towards the lack of practical implementation of the university's language policy. This study will also highlight the ill-preparedness of students for an English-only teaching and learning environment. The tentative empirical data prove that the students also feel that they are at a linguistic disadvantage when entering the tertiary institution. This paper returns to the knotty question regarding language-in-education policies for multilingual societies, which is an ongoing topical issue in national and international contexts.
\end{abstract}

Keywords: multilingualism, academic literacy, education and language, mother-tongue education

\section{Introduction}

The aim of this paper is to reflect on and discuss issues around competing meanings and ideas about multilingual education in the South African higher education system. Previous scholarly and policy debates and conversations around multilingual education in South Africa have paid little attention to the perceptions of students in tertiary institutions. In spite of there being robust and comprehensive policies regarding the treatment of South African languages in the country's 
higher education system, very little (excluding a range of stereotypes) is known about the perceptions of those individuals, particularly students, who are outside the policy-making machinery regarding the handling of languages in the country's university system. We still need to know what the general South African higher education student population thinks about languages in education and why the post-apartheid policy of 11 official languages is not being implemented to the letter in the education system. The premise of this paper is that multilingual education means different things and is understood differently by various stakeholders in the education enterprise. The key question that we seek to address is this: How do different cohorts of South African university students conceptualise multilingual education and what do they expect out of it? In our attempt to respond to this question we draw on the outcomes of a survey that we conducted at the North-West University (NWU) Mafikeng campus where a sample of 500 questionnaires was distributed to available first-year undergraduate students during Academic Literacy lectures. First-year students were selected as the best target group because of their immediate experience of the linguistic transition from a code-switching learning environment at Matric level, to an exclusive use of English at tertiary level. The research adopts Koch and Burckett's (2005) ideas as a theoretical framework. The researchers also suggest a new model solution which complements the learners' needs that may be adapted for the context of the NWU Mafikeng campus students. This research will contribute immensely towards the debate on the role of language in hampering access to university studies.

\section{Language-policy development in South Africa}

To understand the current language policy in democratic South Africa, it is important to give a brief overview of the language-in-education policy introduced by the apartheid government in 1953. This segregated education system saw each ethnic group being taught in its own indigenous language. Its main objective was not to enable Black children to receive education in their languages, but to make sure that they received inferior education (Malherbe 1977, in Kamwangamalu 2000:125). The aim of the Bantu Education Act was "to teach a Black child that he [was] a foreigner when he [was] in White South Africa, or at best stateless; that equality with Europeans was not for him; that there was no place for him [...] above the level of certain forms of labour" (Malherbe 1977, in Kamwangamalu 2000:125). This type of Bantu education benefited first-language speakers of Afrikaans and English because they had to learn two languages, i.e. Afrikaans and English, while Black pupils were tasked with learning three languages, namely Afrikaans, English and an indigenous language. The masked reasons behind Bantu education led to the under-development of African languages in South Africa. Examples of this under-development were the lack of human resources in the homeland schools and the absence of books, as well as the fact that most English native-speaker teachers were withdrawn from the missionary schools and were never replaced. Furthermore, the appointment of the language boards, which occurred after the introduction of the Bantu Education Act in 1953, was perceived as a further attempt at making Black education inferior (even though the UNESCO study (1953) had provided a comprehensive report on how mother-tongue instruction tends to benefit learners) by not adequately resourcing Black education and also by withdrawing native English teachers from the African schools. This under-development contributed to the negative perceptions of indigenous languages within the apartheid government. Black pupils resisted the Bantu Education Act. The Black pupils' resistance to the Bantu Education Act and the apartheid government's determination to impose it led to the Soweto uprising of June 16, 1976, which marked the end of Afrikaans as a language of learning and teaching in Black 
schools and concomitantly boosted the status of English, not only in these schools but also in Black communities (Kamwangamalu 2000:127).

The language issue continued to be an emotive phenomenon in the liberation struggle such that at the birth of the new South Africa in 1994, the government of the African National Congress (ANC) took a bold and ambitious move to change the status of the African languages from inferior to official. Such a move was necessary to redress the linguistic inequalities of the apartheid language policies which had deliberately stifled the development of the indigenous African languages and instead promoted the dominance of Afrikaans and English. One of the tasks of the higher education institutions is to promote communicative competence among all students and staff in all the relevant South African languages. For this purpose, besides its formal academic languages, each higher education institution should identify and promote the learning of one additional or supportive language of tuition (CHE 2001:11). Although this directive is not explicit as to how the promotion of communicative competence should occur, in general it implies that institutions of higher learning should promote multilingualism. It is this directive of the language policy in higher education which has prompted the authors of this article to explore the students and lecturers' perceptions of multilingual education at NWU Mafikeng campus.

It is against this background, and in attempt to break with past discriminatory language-ineducation policies, that the current multilingual language policy was developed and included in the country's new constitution. South Africa has 11 official languages since the Constitution declared it so in 1996. These are Sepedi, Sesotho, Setswana, Siswati, Tshivenda, Xitsonga, Afrikaans, English, isiNdebele, isiXhosa and isiZulu. The Constitution states that all languages are to be treated equally in the workplace as well as in the education system. In addition to the constitution, the Pan South African Language Board (PanSALB) was created in 1995 to oversee the development of the African languages to the status enjoyed by the previously dominant English and Afrikaans languages. The new government demonstrated its commitment to ensuring language equality by establishing structures such as PanSALB and the Language Task Action Group (LANGTAG), whose responsibility was to promote and create a positive environment for the use of the African languages so that they would not end up as only languages of communication, but would also be used as media of instruction in education. The establishment of these two structures is indicative of the government's commitment to promoting multilingualism.

South Africa is one of the few African countries to have promoted the development of indigenous African languages as early as the advent of the country's democratic independence. Many countries prefer the language of the coloniser when they attain democratic independence. The exception in Africa is Tanzania, where Swahili became both an official and national language at independence. Tanzania cannot, however, be compared to other countries on the continent because the origins and development of Swahili as a language of trade make it unique. Most African countries began developing their indigenous languages decades after attaining their independence. Thus we would expect that, two decades later, South Africa would have managed to set in motion the language policies designed in 1994. However, this is not the case. There seems to be polarity between the policy and its implementation, particularly in the case of the language act in education. One of the major reasons for slow implementation is the weakness of "policy glamorisation" within government. According to Cele (2004:39): 
[g]lamorisation of policy is (1) derived from constitutional provisions, (2) based on a concerted effort to make democracy liveable in South Africa, and (3) based on jingoistic mindsets that strive to revive Africa and its cultural identity perceived to be integral in the recognition of indigenous languages. It has also repeatedly persuaded policy-makers to create, through public policy, a string of political expectations based on language equality, a myth that characterises the language policy as flux with Utopia. Besides creating a hypnotic policy effect that defeats policy implementation, policy glamorisation challenges the very political consent to develop indigenous languages that is espoused through the values embodied in the South African constitution.

This means that the policy is over-emphasised and people are concerned with the public buy-in to the policy and neglect the implementation process. This seems to be the weakness of not only the Ministries of Basic and Higher Education but also of the higher institutions of learning in South Africa. Most universities have designed paper-perfect policies that incorporate and promote multilingualism at tertiary institutions, but they fail to put the policy into action. The few that have implemented the policy do so only partially. Cele (2004) cites the case of Stellenbosch University, where Afrikaans and English are used and an attempt to include isiXhosa is still underway, and seems to have been for quite some time. Although recent research shows that Stellenbosch University is currently trying to put their policy into action in the year 2013, with concerted efforts in involving isiXhosa as a functional teaching and learning language, the question is, will they be able to sustain the implementation process? But this is a debate for another era. NWU is another classic case example: Potchefstroom campus has a functioning multilingual system with Afrikaans and English as the dominant languages; however, its sister campus in Mafikeng has a similar situation, with English and Setswana as the majority languages, but the former remaining the dominant language of teaching and learning (LoLT). NWU possesses a glamorous language policy, which suggests that Setswana should be the dominant African language for tuition alongside English; unfortunately, none of this has been put into practice. This seems to be the pitfall of most tertiary institutions. An oftenheard argument is that the students themselves are resisting change and prefer to use English as a medium of instruction. This research found that Mafikeng students feel differently.

Until recently, most lecturers have argued that the African languages themselves are not adequately developed to serve as languages of instruction at tertiary level. We believe this is a lazy argument presented by educators to avoid addressing the concept of diversity in the classroom. Fortunately, innovative lecturers and students at the University of the North, South Africa, proved this lazy theory wrong in 2002, as a Bachelor of Arts degree was designed and developed in the dominant language of the area, namely Sesotho (Ramani and Joseph 2002:234). The students were taught and assessed in their mother tongue and have graduated as relevant and skilled students. The Royal Bafokeng entered into an arrangement with NWU's Potchefstroom campus in 2009 to admit students into the education faculty's foundation phase programme (Mail \& Guardian 2013:23). These students graduated in 2012. If this initiative was a success at our sister campus, which is predominantly Afrikaans-speaking, transferring that experience and knowledge would yield even better results at the Mafikeng campus, where the Department of Setswana has mother-tongue speakers of this language. This proves that the indigenous languages are capable of being used in teaching and learning environments at all 
levels. What is of most significance in the NWU case study is the fact that the students were taught by second-language speakers of Setswana, proving that any tertiary institution can use the language of their choice as long as they have determined, dedicated and innovative members of staff who are not necessarily first-language speakers of the language of tuition.

\section{Multilingualism at tertiary institutions}

There is no doubt that mother-tongue instruction has enormous benefits for learners. The widely cited UNESCO (1953) report succinctly states that mother-tongue instruction in early education contributes to the learners' conceptual and pedagogical development. Being taught in a familiar language enables a child to adapt to the new learning environment, to communicate freely and to create interest in and respect for his/her language. It is for this reason that mother-tongue instruction in South Africa is compulsory from Grade 1 to Grade 5. According to Foley (2004), very little has been done to date in terms of improving mother-tongue instruction. At the foundation and intermediate phase levels, for example, he paints a gloomy picture by pointing out that the National Curriculum Statement has not been translated into African languages. Materials have to be translated in all of the four and nine learning areas in each respective phase. To accelerate the development of these languages, universities should encourage students to register for African language courses, African language curriculums should be modernised, and workshops should be provided for in-service teachers. However, for this to be possible, change has to begin in the curriculum-development phase. The curriculum should accommodate all 11 languages; if translation is the best way to provide access to information, then it must be used wherever possible. Moyo (2000, in Foley 2004) is aware that no single language policy would be practicable for all learners in all provinces. Each province, depending on the linguistic needs of its learners, would design a language policy relevant to its learners' needs. The North West Province, for example, could have Setswana, English and Afrikaans in its policy. Setswana and Afrikaans are the dominant languages in this province, and the NWU Mafikeng campus uses these two languages and English for official business.

There has to be efficacy and practicality in implementing multilingual education, hence Moyo (2002), Alexander (1989), Nhlapo (1945) and Prah (1998) suggest harmonising the Nguni (Zulu, isiXhosa, isiNdebele and Siswati) and Sotho (Sesotho, Setswana, Sepedi) cognates so as to form two language clusters. This, in their view, would reduce the cost of producing teaching and learning materials and also reduce the number of languages for teaching and learning purposes. The notion of 'harmonising' Nguni and Sotho languages is supported by Condauh (1997, in Moyo 2002:156), though he warns that hard-core ethnocentric individuals would also have to be persuaded, and the idea of harmonisation must also be explained clearly to the masses so that the idea is accepted at grass-roots level as well. To develop African languages in education to be on par with Afrikaans and English, wide consultations among researchers and academics should be undertaken (Moyo 2002, Foley 2004). It should be noted that harmonisation should only be used in cases where a standard orthography exists for the mutually intelligible languages. Secondly, in the case of NWU where representation of most of the minority languages is below $2 \%$ (with the exception of Setswana), then the practice of harmonisation will not necessarily be useful. The students may be presented with the option of selecting the dominant language of the region, which is Setswana, as the language of tuition.

Further suggestions regarding multilingualism at tertiary level have been put forward by Koch and Burkett (2005). The authors provide a framework which could be adopted and adapted by 
institutions of higher learning willing to promote multilingualism. They distinguish between two models of multilingual education, namely transitional bilingual education (TBE) and maintenance bilingual education (MBE). The former's outcomes are assimilation and monolingualism, while the latter's are additive bilingualism and biliteracy. For the NWU Mafikeng campus, MBE with some adaptations would be a possible model.

\section{Language context at the NWU Mafikeng campus}

Before discussing the students' perceptions of multilingual education, one has to place their arguments within the relevant linguistic and social context. Hence it is relevant to highlight the existing language context of the NWU Mafikeng campus. The Mafikeng campus is diverse socially, economically, racially, culturally, as well as linguistically. Most of the students at this campus have to negotiate identities within their tertiary environment if they are to succeed in their studies. A majority of the students here are linguistically incompetent for an English-only medium of instruction, as revealed by the results of the Test of Academic Literacy Levels (TALL) in 2012. This test is administered at the beginning of each academic year to all firstyear students to assess their language competency levels as well as their aptitude literacy levels. It is an affordable and reliable means of assessing new university students. However, TALL is not a high-stakes test but a placement test, intended to channel students, if so required, into appropriate academic literacy support courses (Weideman 2006:2). It is through this test that the researchers discovered that most of the NWU Mafikeng students are enrolled ill-prepared for the English-only learning environment they are exposed to at tertiary level. In their secondary education, they were exposed to a code-switching environment between their mother tongue and English. The 2013 TALL results reflect that, out of the 3600 students who sat the test, only $201(5,85 \%)$ students scored above $50 \%$. Of the 201 students who scored above the set pass mark, only 131 managed to score between $50 \%$ and $60 \%$, and only 70 scored above $60 \%$. These figures are disheartening, as they mean that in 2013 , only $5,85 \%$ of the first-year students at Mafikeng campus are linguistically and academically prepared for the tertiary environment.

Unfortunately, with all these statistics reflecting the necessity of implementing multilingualism in teaching and learning at Mafikeng campus, the policy has not been put into action. Instead, it is undergoing the "glamorisation" phase. The policy states that efforts are made at each of the NWU campuses to implement Setswana and Sesotho for teaching and learning purposes; however, these efforts have not yet been seen or experienced by the teaching and learning staff on the Mafikeng campus. There are fluid gaps in the choice of terminology in the policy which allow for different interpretations of the policy by various individuals. For example, the 2012 NWU language policy uses vague escapist statements such as in section 9.1.2.1 (NWU Policy 2012) which states "Although English and Afrikaans are used as primary languages of tuition at the NWU, concerted efforts are made at each of the NWU campuses to (i) implement Setswana and Sesotho for teaching-learning purposes; (ii) to monitor the effectiveness hereof and (iii) to report annually on the progress and outcomes of these projects". Moreover, section 9.1.2.2 (NWU Policy 2012) further states that "Different language modes of delivery are employed at the different campuses to accomplish enhancement and facilitating of access to higher education. These modes are: single-medium teaching, parallel- and dual-medium teaching, as well as educational interpreting services (EIS). (Please note that the expansion of EIS to more teaching programmes takes place according to an agreed set of standards and procedures)". 
The phrase "concerted efforts" in the policy clearly indicates to the reader that the university is aware of the language situation on the various campuses and is addressing the issue, but at its own pace. The policy gives set goals to be achieved in terms of multilingual education; however, it does not give a set time frame as to when these goals should be achieved. This allows for flexibility on the part of management. While it has to be acknowledged that documents and frameworks have to be flexible enough to allow for different forms of implementation, it must be conceded that the resultant vagueness creates gaps in the system. These gaps result in no real progress being made in terms of implementation. Thus it is the researchers' intention to reveal the need for active implementation of the language policy at the NWU Mafikeng campus.

\section{Method and data sample}

The current study is eclectic in nature as questionnaires distributed to the participants consisted of both quantitative and qualitative data to investigate the LoLT-preferences of tertiary students. Permission to conduct the study in the first-year classes was sought from the students and their lecturers. First-year students were selected because they are the considered as the "first grade" students of tertiary education that can clearly reflect the Matric language situation of South Africa. These students are transitioning from secondary to tertiary education and are thus most likely to reflect the entry-level language and literacy levels of students at tertiary level. Senior students would not be appropriate because, due to their exposure to language and literacy interventions, they might not serve as a useful diagnostic. After receiving permission, 500 questionnaires consisting of closed and open-ended questions were distributed in five first-year Academic Literacy classes (AGLE). Section A of the questionnaire required the respondents to state their gender, age, home language, household economic status and the areas in which they lived. The questions in Section B required the students to indicate the LoLT they were taught in at their high school, the language they would have preferred to be taught in and the reasons for that preference. They also had to indicate whether they would be happy to see a change in the language of instruction at Mafikeng campus and, if they answered positively, they had to provide reasons for selecting a particular LoLT. Section C explored the students' attitudes and perceptions regarding the LoLT at tertiary level on a five-point Likert scale.

The 500 participants who responded to the questionnaire, which took about 15 minutes to complete, were drawn from a total population of 36002013 first-year students who sat a compulsory academic literacy level test (TALL) that measures students' academic preparedness for academic work, as mentioned earlier. The quantitative research data was analysed using the SPSS software package. SPSS Statistics is a software package used for statistical analysis; it is a data management and analysis product.

\section{Data analysis and findings}

Out of 500 questionnaires distributed, 486 were returned fully completed and 14 of these questionnaires had to be discarded because they were spoilt. The study had a greater number of female than male participants (57.38\% female). Most of these students' ages ranged between 19 and 26 years and very few were between 30 and 45 years of age. The majority of them came from poor rural areas of the North West Province. The highest percentage in terms of home language distribution was Setswana at $71.6 \%$. The other 10 official languages had a very low representation of below $5 \%$ on the Mafikeng campus. The home language distribution, as 
shown in Table 1, confirms our assumption that the campus is multilingual and multicultural, with Setswana being the dominant language group.

About $95 \%$ of the students who took part in the study came from the North West Province. The majority $(92.8 \%)$ were taught in English at high school and an insignificant number were taught in Setswana and Afrikaans (3.3\% and 1.7\%, respectively). These languages are recognised by campus management for official use, but English remains the sole medium of instruction for all students despite the high failure rate at first-year level. The university's only mitigating effort to curb the high failure rate at this level was to introduce a modified academic skills course, namely AGLE, which has also proved unsuccessful in closing the language-competency gap between secondary and tertiary level.

Table 1. Home language of the participants

\begin{tabular}{|l|l|}
\hline Home language & Number of speakers (\%) \\
\hline Afrikaans & $9(1.9 \%)$ \\
\hline English & $18(3.7 \%)$ \\
\hline isiNdebele & $4(0.8 \%)$ \\
\hline Sepedi & $19(3.9)$ \\
\hline Sesotho & $22(4.6 \%)$ \\
\hline Siswati & $17(3.5 \%)$ \\
\hline Setswana & $346(71.6 \%)$ \\
\hline Xitsonga & $5(1.0 \%)$ \\
\hline Tshivenda & $9(1.9 \%)$ \\
\hline isiXhosa & $20(4.1 \%)$ \\
\hline isiZulu & $10(2.1)$ \\
\hline
\end{tabular}

Although the language policy statement of this campus stipulates that in addition to "English and Afrikaans as primary languages of tuition, concerted efforts are made at each of the NWU campuses to implement Tswana and Sotho for teaching-learning purposes" (NWU Policy 2012), Mafikeng campus has failed to implement a policy that promotes multilingual education. The belief that students have a negative attitude towards the use of mother tongue as medium of instruction has encouraged the hegemony of English as the sole medium of instruction at this campus and has also delayed the implementation of the citizens' constitutional rights to receive education in the language of their choice.

The very high percentage of preference for English as LoLT should be accepted cautiously because there is consistent evidence that most school-leavers who enter South African universities are not adequately prepared for higher education studies (Moyo 1993; Nkosana 1993; Van Schalkwyk et al. 2009; Foxcroft and Stumpf 2005, in Nel et al. 2009:975). Further evidence is drawn from the 2013 TALL results, where only 201 students passed the test out of the 3600 students who took it. This poor performance is not unique to NWU Mafikeng campus; it seems to be the case on the Vaal campus which uses English as LoLT. This is sufficient evidence to prove that Mafikeng students are not adequately competent in the LoLT used on their campus, which is English. Although most of them have acquired basic interpersonal communicative skills (BICS) through involvement in everyday conversation, they lack what Cummins (2001) describes as cognitive academic language proficiency (CALP), which includes reading and writing skills as well as understanding of subject-specific vocabulary. 
Over half of the respondents preferred to be taught in English, as shown in Figure 1.

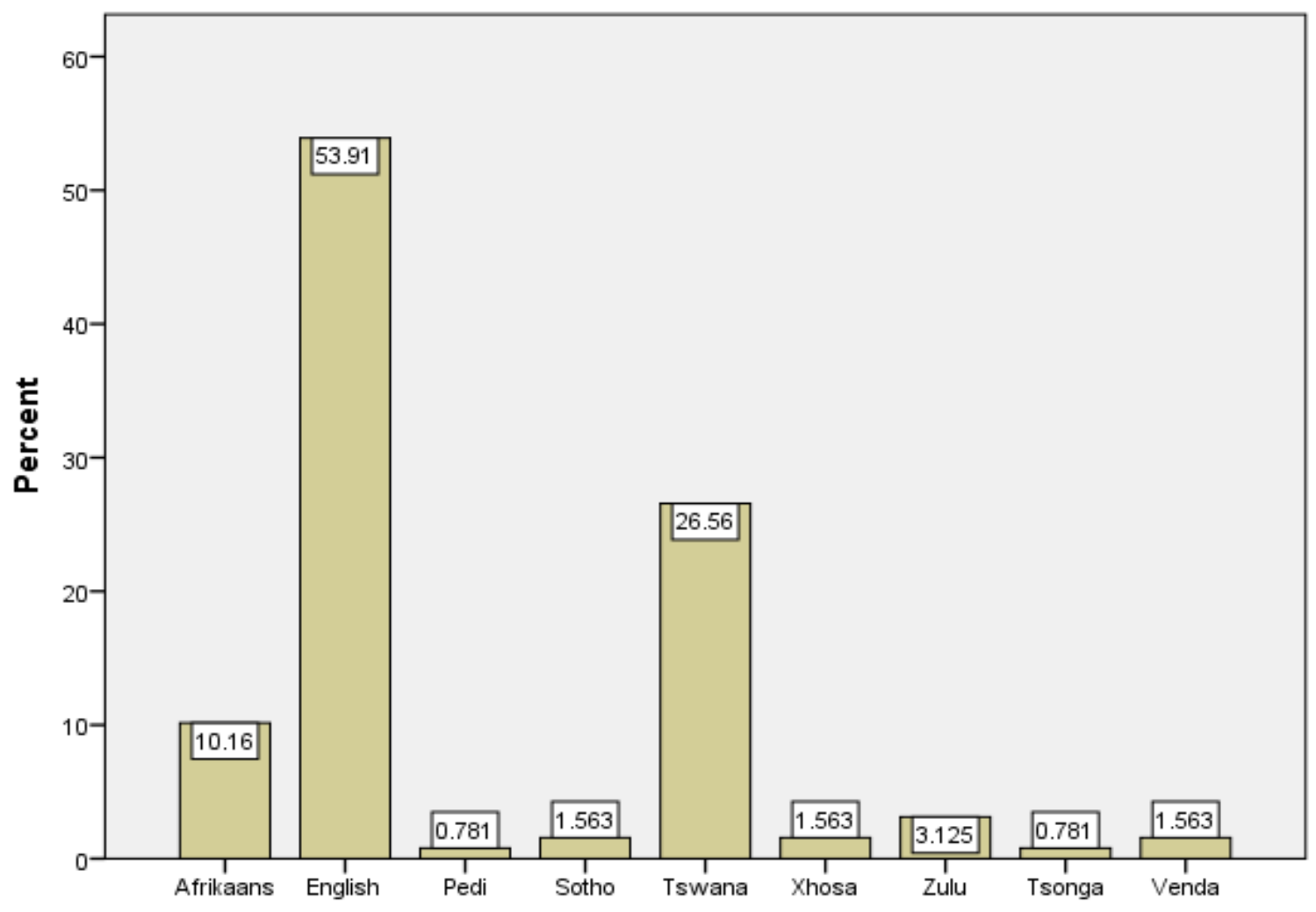

Figure 1. LoLT preference

The strong preference for English, as shown in Figure 1, is influenced by "the dominant position of neo-liberal monolingual medium-of-instruction practices which have created myths and fallacies about the utility of English as the sole language of skills development and training in South Africa" (Ndhlovu 2013:33). The preference for English as LoLT was also observed at the Universities of Stellenbosch and the Free State and the percentages of students' preferences for English (90\% and $73.6 \%$, respectively) were high.

At Mafikeng campus, however, there is some optimism, as Setswana stands out as the secondhighest preferred language compared to the other African languages. One of the factors contributing to its dominance is the geographic and linguistic location of the campus. However, the minimal representation of the other African languages, namely Sepedi, Sesotho, Setswana, isiXhosa, isiZulu, Xitsonga and Tshivenda, does not mean that they should be ignored. These languages could be catered for through various mother-tongue instruction intervention methods.

Considering Setswana as a second medium of instruction should not pose insurmountable challenges in terms of human resources, as the campus currently houses the Department of Setswana which offers translation and interpreting studies at postgraduate level. Using the students' home language as another LoLT would improve their performance and throughput both of which are currently poor, as shown by the first-year pass rate of the last three years which has not gone beyond $60 \%$, and also by the low TALL pass rates. 
Another positive pointer towards an alternative medium of instruction is the students' responses to the question which required them to state whether they would support the use of the mother tongue as an alternative language of instruction if it had the requisite terminology and human, learning and teaching resources. More than half of the respondents $(53.72 \%)$ indicated that they would support mother-tongue instruction. The change in perception seems to suggest that English is a preferred medium of instruction only for instrumental reasons. If Setswana fulfilled the same goals and if it were recognised in business and wider communication, students would choose to be taught in it. There was general agreement in the students' responses that Setswana as an alternative medium of instruction would improve Matric results, enhance understanding of concepts and facilitate the transfer of literacy and numeracy skills. Mentioning that being taught in Setswana would improve Matric results suggests that students are aware of the limit imposed by learning in a second language on educational success.

The increase in the number of students who would prefer an alternative medium of instruction supports our view that a dual-medium policy for Mafikeng campus is a viable option that should be considered. This model is not a reinvention of the language-in-education policy of the National Party, which had negative effects on Black education and did not develop the indigenous languages. The proposed model, on the contrary, will expand the vocabulary of Setswana and encourage language practitioners to engage in meaningful research that will help develop the African languages in terms of vocabulary and technological terminology.

The following section presents suggestions for a dual-medium model that the campus could adopt to ensure cognitive development of students, accelerate throughput and decrease the dropout rate.

\section{Recommendations}

The target group for this model is the first-year AGLE students. This is a compulsory year course for all first-year students. Its main aim is to enable students to comprehend academic discourse by offering assistance with reading, writing, referencing and dictionary skills, as well as with grammar. The course has not been very effective in addressing the linguistic inadequacies caused by the schooling system. The proposed model that will be described in this section is meant to enable students (especially students with very poor competency in English) to acquire these essential skills in the language that they understand.

The dual model will have both English and Setswana as media of instruction for AGLE students. Lectures will be presented in English with Setswana subtitles using multimedia equipment. Notes, tests and assignments will be written in both languages and if translation is required, this could be carried our by the Department of Setswana. For students who speak other African languages, a model similar to Ramani and Joseph (2005) could be adopted. This is a dual model of instruction where an instructor is present during lectures. The translator would have familiarised him-/herself with the subject content well in advance. For example, where the lecturer presents Setswana lectures, the translator will provide an English version of the lecture, and vice-versa. Its main advantage is that students competent in English and an African language will assist in translating English texts into their own languages, thereby creating a language resource bank for future use as well. This model will enable students to develop to their full potential through drawing on their home language as a resource for cognitive 
development, for epistemological access, and for better access to English as a language of academic discourse (Koch and Burkett 2005).

\section{Conclusion}

Unlike most universities in South Africa, NWU has an approved language policy. However, the major flaw with the implementation of this policy is the fact that it is inactive. The university needs to put structures in place that will ensure that the policy is implemented. In conclusion, it must be noted that African languages must not be confined to basic interpersonal communicative skills (BICS), but be extended to cognitive academic language proficiency skills (CALP) (Cummings 2001). This can only be achieved if these languages are used for academic purposes and extensive research is undertaken to develop them to a level where they can also be used in science and technology. A language will only develop when used; languages are dynamic and they adapt to new environments. This means that African languages have the capability of expanding their vocabulary to suit any teaching and learning environment. The students are willing to be taught in their mother tongue only if the languages are able to provide the same global services and skills as English. As highlighted in this paper, African languages have entered the arena of service and skills delivery and, hence, they can be used and transformed to suit the learning needs of the students.

\section{References}

Alexander, B. 1989. Language policy and unity in South Africa/Azania. Cape Town: Creda Press.

Cele, N. 2004. 'Equity of access' and 'equity of outcomes' challenged by language policy, politics and practice in South African higher education: The myth of language equality in education. South African Journal of Higher Education 18(1): 38-56.

Council on Higher Education (CHE). 2001. Language framework for South African higher education. Pretoria: Council on Higher Education.

Cummings, J. 1981. Empirical and theoretical underpinnings of bilingual education. Journal of Education 163(1): 16-29.

Cummins, J. 2001. Bilingual children's mother tongue: Why is it important for education? Sprogforum 19: 15-20.

Foley, A. 2004. Language policy for higher education in South Africa: Implications and complications. South African Journal of Higher Education 18(1): 57-71.

Director: Institutional Language Directorate. 2012. Institutional language policy of the NorthWest University. RB Share: 2P/2.5 - Language Policy

Kamwangamalu, N.M. 2000. Language policy and mother-tongue education in South Africa: The case for a market-oriented approach. Georgetown: Georgetown University Press. 
Koch, E. and B. Burkett. 2005. Making the role of African languages in higher education a reality. South African Journal of Higher Education 19(6): 1089-1106.

Mail \& Guardian. 15-21 March 2013. Mother tongue education no longer a pipe-dream. Research for communities. Advertising supplement in the Mail \& Guardian. p.23.

Moyo, T. 1993. What to teach the first-years? Crux. pp. 34-38.

Moyo, T. 2002. Mother tongues versus an ex-colonial language as media of instruction and the promotion of multilingualism: The South African experience. South African Journal of African Languages 22(2): 149-160.

Ndhlovu, F. 2013. Beyond neo-liberal instructional models: Why multilingual instruction matters for South African skills development. International Journal of Language Studies 7(4): $33-58$.

Nel, C., C. Troskie-de Bruin and E. Bitzer. 2009. Students' transition from school to university: Possibilities for a pre-university intervention. South African Journal of Higher Education 23(5): 974-999.

Nhlapo, J. 1945. Nguni and Sotho: A practical plan for the unification of the South African Bantu languages. Cape Town: African Bookman.

Nkosana, A.L. 1993. The need for bridging courses. Crux. pp. 29-30.

United Nations Educational, Scientific and Cultural Organisation (UNESCO). 1953. Monograph on Fundamental Education. Vol. 8. Paris: UNESCO. p.156

Prah, K.K. 1998. The missing link in African education and development. Johannesburg: Witwatersrand University Press.

Ramani, E and M. Joseph. 2002. Breaking new ground: Introducing an African language as medium of instruction at the University of the North. Perspectives in Education 20(1): 233240.

Van Schalkwk, S., E. Bitzer and C. Van der Walt. 2009. Acquiring academic literacy: A case of first year extended degree programme students. Southern African Linguistics and Applied Language studies 27(2): 189-201.

Weideman, A. 2006. Assessing academic literacy in a task-based approach. Language Matters 37: $1-21$. 